\title{
Electrical Storm Simulation to Improve the Learning Physics Process
}

\author{
Miriam MARTÍNEZ MUÑOZ, María Lourdes JIMÉNEZ RODRÍGUEZ, \\ José Antonio GUTIÉRREZ de MESA \\ Computer Science Department, University of Alcalá \\ Alcalá de Henares, Spain \\ e-mail: \{miriam.martinezm; lou.jimenez; jantonio.gutierrez\}@uah.es
}

Received: February 2013

\begin{abstract}
This work is part of a research project whose main objective is to understand the impact that the use of Information and Communication Technology (ICT) has on the teaching and learning process on the subject of Physics. We will show that, with the use of a storm simulator, physics students improve their learning process on one hand they understand storm phenomenon, and on the other hand they assimilate in better way physics ideas. Computer technology is a positive supplement to bridge the gap between education and the technological world in which we live. Computerassisted technologies at the university offer students a great access to information, an eager motivation to learn, a jump-start on marketable job skills and an enhanced quality of class work.
\end{abstract}

Keywords: virtual laboratory, technologies, education, teaching, physics, simulation.

\section{Introduction}

Nowadays there is a consensus than the formation of $20^{\text {th }}$ Century cannot just be reduced to the formation or teaching literacy in the written or printed culture. Times have changed and we live in a period of historical age which imposes new waysand cultural contents transmitted through the non printed media.The actual outlook at the beginning of the XXIst Century shows a completely different scenariothanindustrial society of the last two centuries (Wenning, 2005).

History has demonstrated the use of computer science, especially with the progress and development of telecommunications that lead all processes. Telecommunications are well developed and have their application in the different fields of knowledge.

In education the advance and development of new models, new techniques and methods is happening. These changes have a positive effect on the way teachers teach and students learn (Adelli, 1998).

Education in all the areas of knowledge has benefited from the innovative technologies. With the creation of new areas in which teachers and students can have new visual ways of the studied concepts (Alanis, 2000). Simulation allows the students to develop their own educational competences according to their science level. 
Experiments are usually developed in laboratories where people and material resources are involved. On many occasions laboratories need many resources that they cannot afford. Also the setting up of machinery and mechanism to organize practical sessions contains certain risks associated with the fact that this machinery is manipulated by novices, not experts. This can produce both personal injuries and material damage.

The creation of simulation laboratories where students will be involved in inquirybased science investigations will help in solving the above problem. Working in these laboratories will help students to improve and optimize laboratory tools

The main objective of this project is to show that the use of a simulator helps to improve the understanding of concepts related to subject of physics.

To achieve the objective we have mentioned above it is necessary to follow these secondary objectives:

- To understand the impact of the use of the new technologies in the students learning process in the subject of physics.

- To develop students' high-level computer skills and competence (student's expertise) in ICT and in physics.

- To analyze the use of specific technological recourses as part of a strategy in teachingthat helps to achieve learning.

- To determine if the use of external representation (images, animations, simulationsand actual experiences) helps to understand the concepts of physics.

This paper is structured in 5 sections. The following analysis, which is done in Section 2, demonstrates how the use of determined technical resources in a didactic unit, "Electrical Field", helps to improve the understanding of disciplinary concepts. Specially, in Section 3 we show the influence of external representation (images, animations, simulations) that has been used to register, analyze and explain the Electrical Field phenomena are intended to improve the concepts of electrical load, electrical potential, thunder, lightning and beam. Section 4 includes the results we have achieved and conclusions are shown in Section 5. Section 6 deals with future investigations.

\section{The System}

As we mentioned in Introduction, the main objective of this project is to show that the use of a simulator helps to improve the understanding of the physics concepts.

In a classroom or in a real laboratory, teachers cannot reproduce some important physics phenomena, but with a virtual laboratory (in this case, applets) they can (Cabero et al., 2000).

In this work we focus on exposing a methodology that facilitates the student's feedback on the chosen didactic unit. With the use of a storm simulation students can achieve the knowledge by following their own way of learning, so starting from different levels it is possible to achieve the final claimed level (Shin et al., 2012).

The simulator is a java applet where we can develop all the important concepts about Electrostatics (Electrical loads, potential difference, electrical field, Coulomb's law and electrization of the matter). 
These concepts due to the fact that the ideas cannot be addressed and it is not possible to represent them in classroom, therefore it is very difficult for students to understand them.

The simulator we have used, "Storm Simulator" has been developed with Java technology. The version of the JDK that we have used is the 1.6 (called Java SE 6.0).

The basic environment of the JDK's Java that Sun provides is composed by tools in text mode:

- Java, interpreter that executes programs in byte-code.

- Javac, Java compiler that converts the code source into byte-code.

- Javap is a decompiler of byte-code to code Java source.

- Javadoc is an automatic generator of HTML documents from the code Java source. Applet viewer is an applet viewer.

The development environment we have used is NetBeans version 6. NetBeans is an open source platform that was born in 2000 as a project of Sun Microsystems.

The first screen of our storm simulator is shown in Fig. 1. In this screen we can value the humidity, temperature, ground electrical load and electrical field which are magnitudes with initial value zero.

In this window we can see parts: the left one with the data and the right one with an image. Once the data are introduced, we will be able to begin the simulation.

Once the values have been introduced, we click on start button, and this button changes its name tree of states which represents the different states of the process.

Our storm simulator is composed by 23 images;one of them is shown in Fig. 3.

With this tool we can manage the academic objectives of the didactic unit, so students actively learn all these concepts while they use the simulator.

The basic concepts of Electrostatic are shown in Fig. 4.

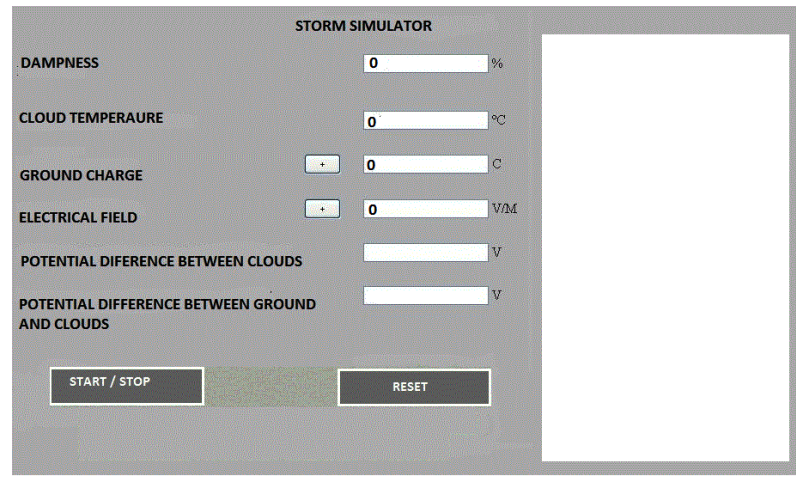

Fig. 1. Electrical Storm Simulator.

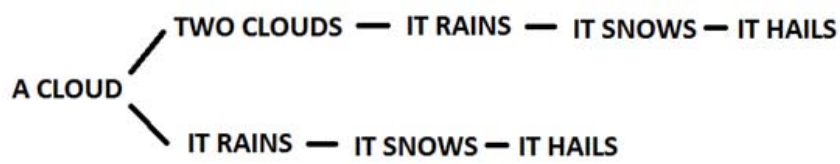

Fig. 2. Tree of states. 


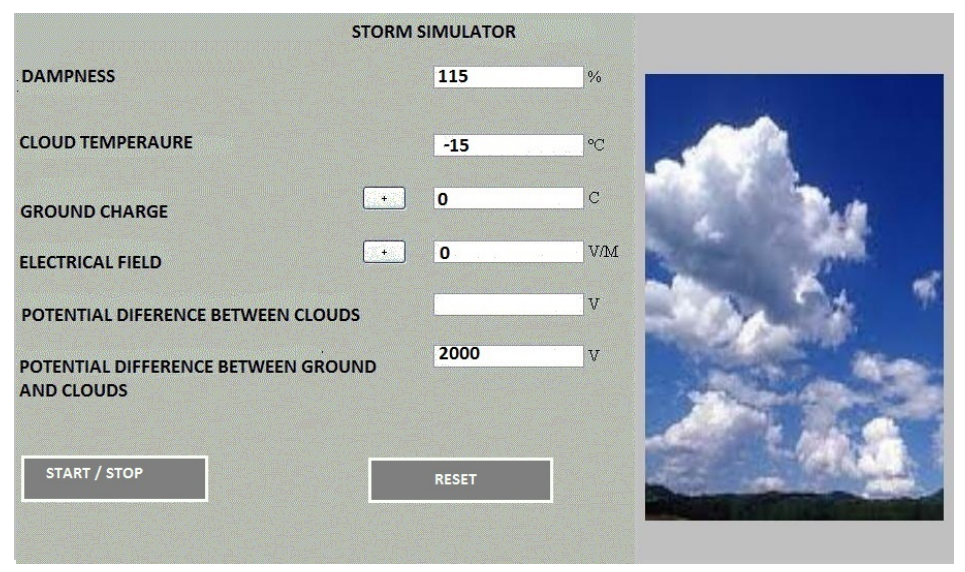

Fig. 3. There are several clouds.

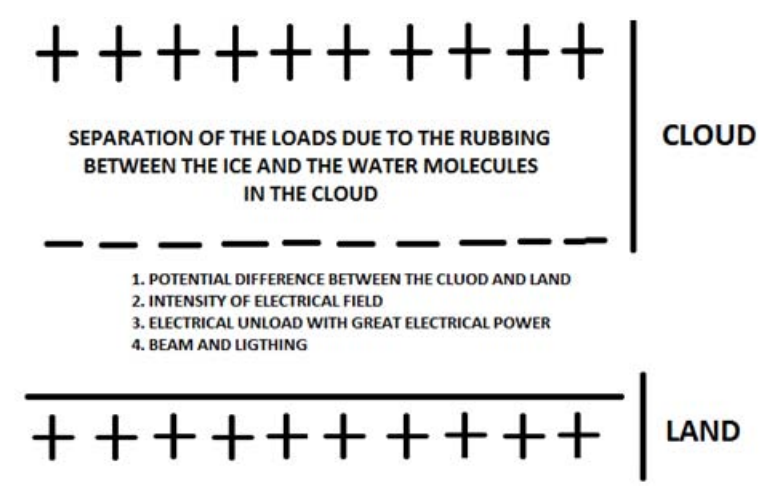

Fig. 4. Developed concepts with the storm simulation.

The concepts we have shown with our storm simulator are:

- An electrical storm is more commonly known as a thunder or lightning storm. An electrical storm may or may not present thunder, but lightning can still happen in the lack of thunder. It is created from the combination of atmospheric processes and dry air.

- Thunder is a direct result of lightning and it happens when clouds are separated and rejoined during an electrical storm. The friction created among different weather occurrences creates a build up of energy which results in an electrical storm.

- Lightning is a chaotic and dangerous aspect of weather. Lightning occurs most frequently during thunder storms where lightning is created as a discharge of built up energy due to the separation of positive and negative charges which are generated inside the thunder storm.

- A separation of electrical charge takes place due to the different rates of rising and falling within a thunder storm. These collisions within the thunder storm cause 
these particles to build up electric charge. As the thunder storm grows, intense electrical fields can develop within it. Air, however, is a good insulator, and the electrical potential between clouds and ground must be of levels among ten to hundreds of millions of volts before the insulating properties of the air break down and an ionized conductive channel is established for the current to flow between the two charges.

\section{The Experiment}

Physics is considered by most of the students as a difficult and abstract science. This difficulty is due to the fact that physics makes use of a scientific and mathematic language with unfamiliar terminology and the lack of interest of the students caused by the disconnect between physics in classroom and the phenomena which we observe outside classroom.

When the students are asked about this science they say it is an interesting subject but very difficult because there are lots of physical phenomena they cannot observe in their life and they cannot imagine them (Pérez, 2005).

In a classroom or in a real laboratory, teachers cannot reproduce some important physics phenomena, but with virtual laboratory (in this case, storm applet) they can (AA.VV., 1999).

This experience consists of:

- Analyzing the use of certain technological recourses as part of strategy in teaching that allows achieving comprehensive learning.

- Determining if the use of external representation (images, animations, simulationsand actual experiences) helps students to understand physical concepts.

All the students studying the subject, who were in the third year of the teaching degree, took part in the experience. There were twenty students: 18 students had never studied physics and 12 of them had not studied mathematics for several years and their ages were among 20 and 40 years old. Because of their lack of knowledge it was necessary to make explanations be slower and the teacher had to explain the didactic unit deeper.

The used methodology was the following:

- Thefirst day, students were asked to take a written test of 10 questions, so the teacher could assess the knowledge they had about these concepts. Students also answered a questionnaire on their attitudes towards sciences.

- Physics was taught for two weeks through magisterial classes. The teacher developed the didactic unit using the blackboard with several books. After students studied the material and practiced its application using variety of exercises they were asked to take a written test of 10 questions again.

- During the following week the electrical storm simulator was used. The teacher explained the students how to use the simulator, the parameters they had to manage and the concepts they were going to acquire. Finally, students took another test to evaluate their concepts and another questionnaire about their attitudes toward physics. 
- At this time we had 3 answered tests: previous, during and after experiment. We were able to verify if the objective was reached and we could compare the results from the two previous texts done by students to check them with the use of the virtual laboratory. We were able to see a change in their attitudes towards physics.

- Two months later, students took again the test of 10 questions with principal concepts about "Electric Field". We could observe that the students had not forgotten most or the concepts.

\section{Results}

\subsection{Academic results}

The results obtained in the 3 steps of the research are shown next.

As we mentioned above we could compare student's knowledge with the tests they were asked to make. In Fig. 5 these results are shown.

The left most bar shows the result obtained by each student at the beginning of the investigation; the middle bat of the graphical shows the score of each student once the physics content was explained and the right bar shows the obtained results when the use of the simulator was ended.

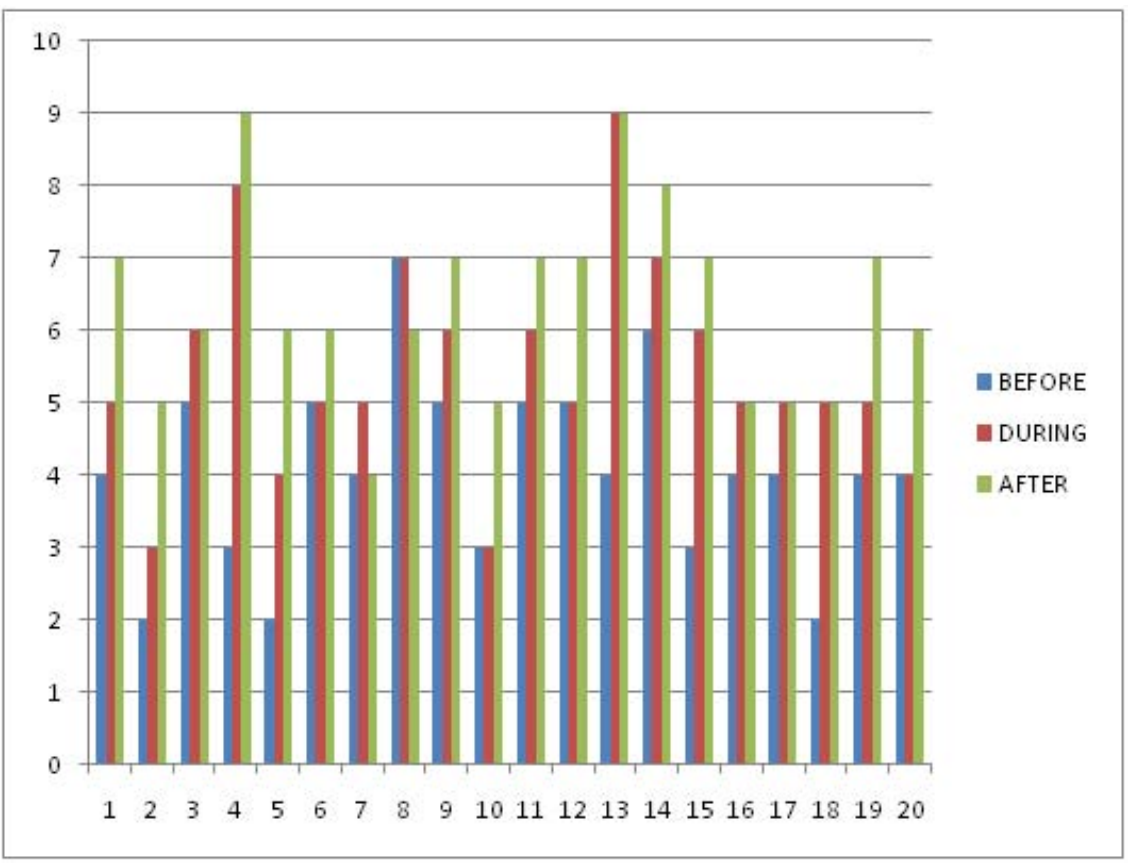

Fig. 5. Results after each questionnaire. 
Students got better results after using the simulator than after the class. Students had to do three tests:

1. At the beginning they did the first, before teacher explanation.

2. The second test was made after teacher explanation.

3. The last test was made after using the simulator.

So, we can compare the results after each phase.

There were four students who did not improve with the applets and only 2 students had worse results with the simulator than with the magisterial class.

We can see the progress of each student, thanks to the use of the storm simulator.

The experience in the study provides the setting for the aspects of pedagogic didactics that lay the foundation of educational practices whose teaching strategies include the use of the ICT to impact comprehensive learning that contribute to the formation of the students' physics conceptual knowledge.

Two months later students were asked to take another test as we wanted to knowif they could remember the most important electric concepts. The results are shown inFig. 6.

As we can see in Fig. 6, two months later, $75 \%$ of the students obtained grades equal to or higher than 5; this means that with our storm simulator we obtain good results.

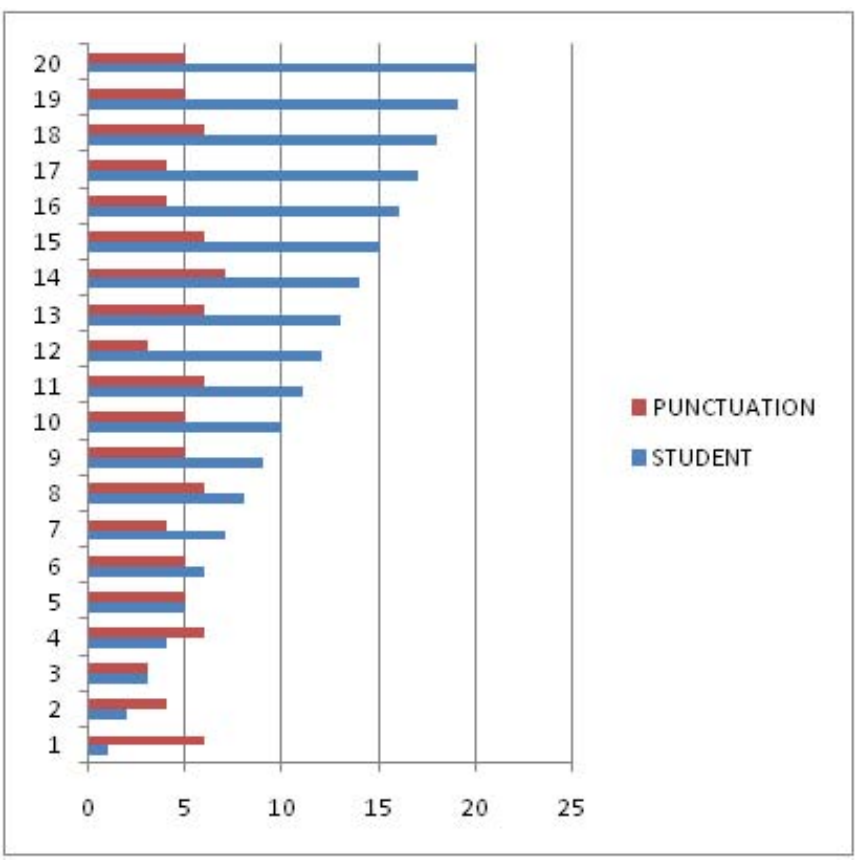

Fig. 6. Results after two months. 


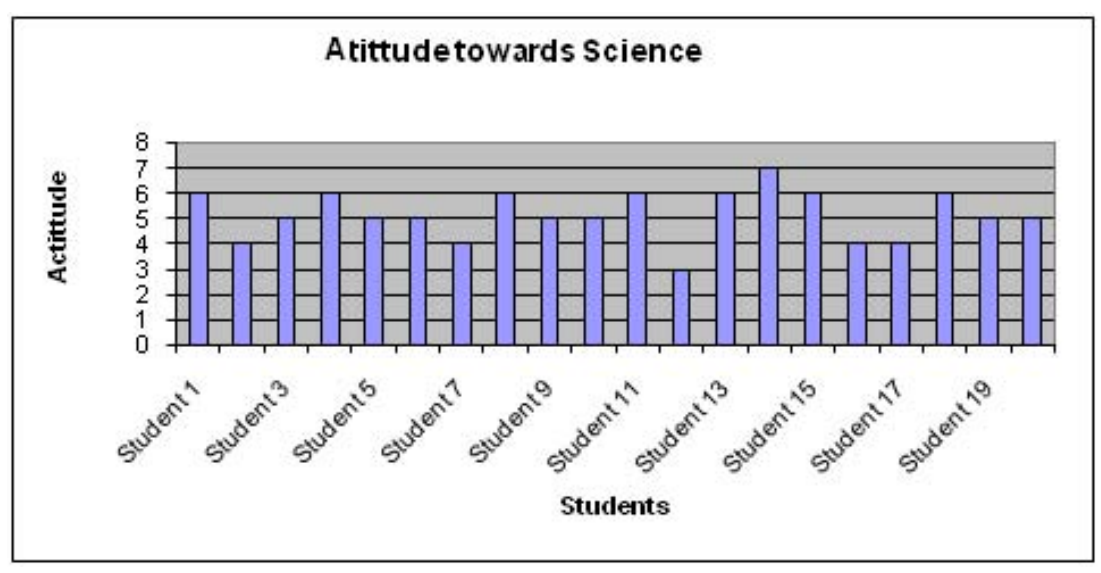

Fig. 7. Attitude towards Science after using the simulator.

\subsection{Attitudinal results}

The interest of the students towards physics decreases progressively as they grow. Their innate curiosity and interest in science is gradually being replaced with lack of interest, apathy, boredom and scholar failure at the beginning of secondary (Rosado, 2001), a factthat worries nowadays (López et al., 2001).

We wanted to know if using of ICT could improve their interest about science. The students not only answered tests about important concepts, but also about their attitudes towards physics has changed. They were asked to answer 2 questionnaires, before and after using the storm simulator.

The first bar shows the evaluation of each student towards science and the second one shows their attitude at the end of the research.

Students did not like very much studying physics, in fact, they were not interested in it, but after using ICT, their interest towards physics changed.

\section{Conclusions}

By analyzing the data of the completed experiences signification statistical achievements in the performance of the students that took part in the experimental groups are observed.

We used the U-Mann Whitney probe to analyze the attitude towards the science and the statistical $\chi 2$ to analyze the concepts students approached.

In both groups an appreciable impact in the use of ICT in the understanding of the different didactic units is shown.

This work has permitted us to know the impact that the use of new technologies has in the process of teaching and learning. It is observed that the application of technological resources to represent physical phenomena in actual settings contribute to the improvement of the comprehensive learning of the concepts of physics in the students during the last year of secondary school and teachers training colleges. 
It is not a question of replacing the figure of the professor neither in the classroom nor the magisterial classes. With ICT our goal is that the students not only will learn the obligatory concepts in class but also will like the science and the inquiry-based learning.

Besides these results, additional conclusions may be drawn. First, the decrease of the improvement and its occurrence in the secondary school must be considered. We may argue that older students are more acquainted with new technologies and their motivation increases their success in using these technologies. Younger students may not feel as motivated as the older with applets and this may explain their lower (but also important) improvement.

We are aware that the number of experimental groups was not very high (just 2), but we consider that this tool offers a considerable flexibility that might make it easier to incorporate it into many other learning situations that will allow to extend this study ant its conclusions.

\section{Future Investigations}

This application was evaluated with students on campus classroom environments to explore physical simulations feasibility and to get valuable feedback from the potential users. Our experience with this project demonstrates that most learning pedagogies from constructive learning and conversation theories can be adapted for a mobile learning environment.

The key is to understand the strengths and weaknesses of a particular technology, while deploying good pedagogical practices to achieve specific learning goals. This storm simulator, well simulators in general, cannot reproduce the reality, they only can simulate the phenomenas.

In the future we may implement this experience with virtual students and with secondary school students.

\section{References}

AA.VV. (1999). Las nuevas tecnologías para la mejora educativa, en la educación flexible y a distancia. Actas de EDUTEC 99. Sevilla: Kronos.

Adelli, J. (1998). Nuevas tecnologías e innovación educativa. En Organización y Gestión Educativa, 1, 3-7.

Alanis, A. (2000). Estrategias Docentes Y Estrategias De Aprendizaje. Contexto Educativo, 10.

Cabero, J. et al. (Coords) (2000). Las Nuevas Tecnologías Para la Mejora Educativa. Algunas Comunicaciones Y Ponencias Del Congreso Edutec99. Kronos, Sevilla.

López, P., Palmero, R.R., Rodríguez and José, J. y S. (2006). Las Tic Como Agentes de Innovación Educativa. Sevilla, Junta de Andalucía, Consejería de Educación.

Montero O’Farrill, J.L. (2008). Las Herramientas de Autor en el Proceso de Producción de Cursos en Formato Digital.

Pérez, A. (2005) Evaluación Nacional de Actitudes y Valores Hacia la Ciencia en Entornos Educativos. FECYT, Madrid.

Rosado, L. (2001). Didáctica de la Física. UNED, Madrid.

Shin, N., Sutherland, LeeAnn M., Norris, C.A., Soloway, E. (2012). Effects of game technology on elementary student learning inmathematics. British Journal of Educational Technology, 43(4), 540-560.

Wenning, C.J. (2005). Implementing inquiry-based instruction in the science classroom: a new model for solving the improvement-of-practice problem, Journal of Physics Teacher, Education Online, 2. 


\section{Appendix}

The following questionnaires are the test the students did about their attitude and concepts:

\section{QUESTIONNAIRE ABOUT THE ATTITUDE TOWARDS SCIENCIE}

\section{- FIRST TEST}

NAME

AGE

$0=\mathrm{I}$ don't know

$1=\mathrm{I}$ total disagree

$2=\mathrm{I}$ disagree

$3=\mathrm{I}$ am not sure

$4=$ I agree

$5=\mathrm{I}$ total agree

First test about the attitude towards the Science

\begin{tabular}{|c|c|c|c|c|c|c|}
\hline & 0 & 1 & 2 & 3 & 4 & 5 \\
\hline \multicolumn{7}{|c|}{ 1. We have a better world to live through science } \\
\hline \multicolumn{7}{|l|}{ 2. Nobody likes science } \\
\hline \multicolumn{7}{|l|}{ 3. Science helps to save time and effort } \\
\hline \multicolumn{7}{|l|}{ 4. Science is very difficult to learn } \\
\hline \multicolumn{7}{|l|}{ 5. Thediseasecan be cured through science } \\
\hline \multicolumn{7}{|c|}{$\begin{array}{l}\text { 6. The greater scientific knowledge exists, there } \\
\text { is more concern for our world }\end{array}$} \\
\hline \multicolumn{7}{|l|}{ 7. Science is not boring } \\
\hline \multicolumn{7}{|l|}{ 8. Science helps people every where } \\
\hline \multicolumn{7}{|l|}{ 9. The science is sound } \\
\hline \multicolumn{7}{|l|}{ 10. I feel sick just thinking about science } \\
\hline \multicolumn{7}{|l|}{ 11. Curiosity is the essence of science } \\
\hline \multicolumn{7}{|c|}{ 12. People live more healthily through science } \\
\hline \multicolumn{7}{|l|}{ 13. Science stimulates curiosity } \\
\hline \multicolumn{7}{|l|}{ 14. Science defends us from superstition } \\
\hline 15. Science seems to be very interesting & & & & & & \\
\hline
\end{tabular}

\section{- LAST TEST}

NAME

AGE

$0=\mathrm{I}$ don't know

$1=\mathrm{I}$ total disagree

$2=$ I disagree

$3=\mathrm{I}$ am not sure

$4=$ I agree

$5=\mathrm{I}$ total agree 
Last test about the attitude towards the Science

\begin{tabular}{|c|c|c|c|c|c|c|}
\hline & 0 & 1 & 2 & 3 & 4 & 5 \\
\hline \multicolumn{7}{|l|}{ 1. You need to be taught in Teaching Physics content } \\
\hline \multicolumn{7}{|l|}{ 2. We will serve utility you studied Physics } \\
\hline \multicolumn{7}{|l|}{$\begin{array}{l}\text { 3. Everyone should have knowledge of physics, not } \\
\text { only future physicists }\end{array}$} \\
\hline \multicolumn{7}{|l|}{ 4. Physics has favored the development of humanity } \\
\hline \multicolumn{7}{|l|}{ 5. Work in a science laboratory } \\
\hline 6. The scientists' work has some sort of special feature & & & & & & \\
\hline
\end{tabular}

\section{QUESTIONNAIRE ABOUT THE CONCEPTS OF ELECTRIC FIELD}

\section{- FIRST TEST}

NAME

\section{AGE}

1. A field is:
a. A playground
b. A physical concept that explains the existence of contact forces
c. Any region of space whose points are characterized by the value of a physical variable
d. A concept that originates in the positive charge
e. The temperature

2. Action at a distance is:
a. The interaction between bodies that are not in physical contact
b. Telepathy
c. A remote control system
d. The interaction between the electric field and potential
e. The electric field output by the positive charge

3. The lines of force of the electric field:
a. Moving loads
b. Are equipotential
c. Intersect at right angles
d. They cannotinterbreedwithequipotential
e. They start in the positive charges

4. In regions of higher electric field strength:
a. The lines of force are even stronger
b. The lines of force appear closer together
c. There are fewer burdens
d. The potential disappears
e. They originate force lines

5. The existence of the electric field is proposed to explain:

a. That the positive charges are the sources of the field

b. Electric charges interact even when no physical contact between them 
c. Rejected because loads are of the same type and are attracted when they are of different types

d. The reason why they are difficult to observe electrostatic phenomena

e. The properties of the equipotential lines

6. The electric potential is:

a. A scalar field

b. A vector field

c. Anequipotential

d. everything but a field

e. The medium allows electric charges interact with each other

7. The lines of force of a uniform electric field:
a. Are equidistant from each
b. They have to be straight
c. They have to be circular
d. Are parallel to the equipotential lines
e. Are thinner than those of non-uniform fields

8. The electrical potential energy is defined as:
a. The lines of force
b. Equipotential lines
c. It is the work that must be done to move a charge from infinity.
d. The ratio between the force and a positive test charge very small
e. Action at a distance

9. What kind of loads exist in nature:
a. Positive
b. Negative
c. No, the bodies are always neutral
d. Depending on the body that are
e. Positive and negative

10. Coulomb's Law states:
a. The force between point charges always Attraction
b. The strength does not depend on the distance between loads
c. The force between point charges always repulsive
d. Force is measured in Joules
e. It is measured in Newton and can be push and pull

- SECOND TEST

NAME

AGE

1. In certain popular science magazines said that a black hole is a body so dense that anything that comes close to certain distance, is absorbed and disappears forever. If an electron falls into a black hole, would electrical charge disappear?
a. No, because the electron mass is negligible
b. Yes, because it exceeds the limit of distance
c. No, because the electron is a point charge 
d. It depends on the electron charge

2. Is it possible that the electric charge of a particle is from $6.10-19 \mathrm{C}$ ?

a. No, because it is a value too small

b. Yes, because the charges can be positive or negative

c. No, because the charges are negative

d. The load is measured in Joules

3. Can you cut the electric field lines at the same point?

a. The electric field cannot be represented by lines of force

b. Yes, because the electric field lines are closed

c. No, because the electric field lines are open

d. Depends on the environment in which the loads are created said field

4. Do you have real meaning the electric potential at a point?
a. No
b. Yes
c. Depends on the medium
d. Do not know

5. Can determine the potential in a point in space called the value of the electric field intensity at that point?
a. No, the electric field can be determined by the value of the potential known
b. According to the formulas we use
c. Yes, the two concepts are related
d. There is no formula that relates

6. By aligning two charges of the same sign, is the electric potential energy increase or decrease?
a. Increases
b. Decreases
c. Depends on the electric field intensity
d. As in the case of two charges of opposite sign

7. The electric charge acquires an airplane could produce annoying shock on landing. What are kinds of small strands that carry aircraft wings on the back?
a. To cushion the fall in accidents
b. To decorate the plane
c. To channel the electrostatic energy and prevent electric shock
d. Do not know

8. Is it possible to build a screen to protect the electric field?

a. Yes, using the concept of the Faraday cage

b. No, because the electric field strength is always very high

c. No, because it is invisible

d. The electric field causes no damage

9. What allows us to determine Coulomb's Law?

a. The distance between two electric charges

b. If loads are attractive or repulsive 
c. Electric field intensity

d. The force with which they attract or repel two electric charges

10. What drive the electric charge is measured, electric power, electric potential and electric field intensity?
a. C, m, V y N/C
b. C, N, V y N/m
c. $C, N, J$ y N/C
d. $C, N, V$ y N/C

\section{- LAST TEST}

NAME

AGE

1. If you rub a glass rod with a cloth, which of the two bodies is electrified, the bar or the cloth?
a. Bar
b. The cloth
c. Both
d. None

2. By bringing an electrified rod pendulum consists of a ball of yarn and a plastic material is an attraction of the ball toward the bar electrified. Why?
a. Because they are loaded with the same electric charge
b. Because air is blown at that time
c. Because has moved the bracket that holds the pendulum
d. Because they are loaded with different electric charge

3. Can we say that work and potential are the same thing?
a. Yes
b. They have nothing to do
c. No, although related
d. Yes, because the unit is the same

4. Of the three points on the image, which one is more intense electric field?

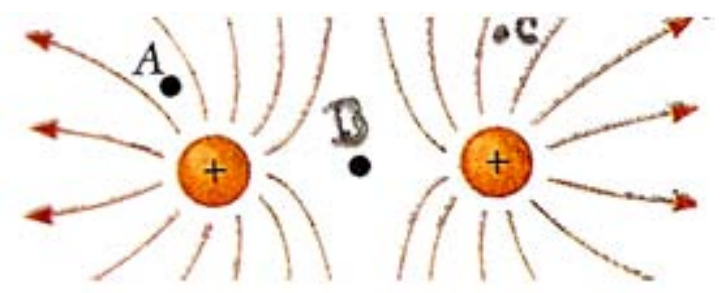
a. A
b. B
c. C
d. There is no difference between the three points

5. In a region of space, the electric field strength this zero. Should be zero electric potential also? 

a. No
b. Yes
c. Depends on the medium in which electric charges are
d. Only if the distance between the charges is small

6. Ifyou want to perform an experiment with no interference from electric fields, suffice? Build a metal box inside the experiment?
a. Yes, the concept of the Faraday cage
b. No, because there would be more interference
c. Depends on the size of the cabinet
d. Electric fields no interference

7. Considering the electric field of the atmosphere in a flat area near the surface of the Earth, when we ascend, what happens to the electric field strength and potential?
a. The electric field intensity increases and decreases potential
b. The electric field strength decreases and increases potential
c. The electric field strength increases and increases potential
d. The electric field strength decreases and the potential decreases

8. Can determined electric field strength at a point in space called the electrical potential value at that point?
a. No electric potential can be determined by known field value
b. According to the formulas we use
c. Yes, the two concepts are related
d. There is no formula that relates

9. Is it possible that the electric charge of a particle is $-6.10-20 \mathrm{C}$ ?
a. No, because it is a value too small
b. Yes, because the charges can be positive or negative
c. No, because the charges are positive
d. The load is measured in Joules

10. When can we say that the force between two electric charges is attractive?
a. It depends on the value of the constant $\mathrm{K}$
b. If the charges are the same sign
c. If the charges are of opposite sign
d. If the gap is small loads 
M. Martínez Muñoz got a five-year degree on Physics from the University Complutense of Madrid. She holds the position of associate professor at the Informatic Faculty, Sciences Computation Departament, Alcalá de Henares since 2006. Her fields of research interests educational technologies, physic phenomena and programming languages. She has participated as an investigator of one project and she is author of more than 10 research papers most of which are published in international journals and international conferences.

She has worked as titular professor of Physic at Cardenal Cisneros University, Alcalá de Henares since 2007. She is author of several research paper which are published in Pulso.

J.A. Gutiérrez de Mesa obtained a university degree in Computer Science from the Polytechnics University of Madrid, Documentation from the Alcala University, Mathematical degree from de University Complutense of Madrid and a PhD from the Mathematical Department of the University of Alcala. From September 1992 to April 1994 she worked as a lecturer in the Mathematical Department of the Alcalá University, and before she joined the Computer Science Department of University of Alcalá as permanent professor. From 1998 to 2001, has the principal of Computer Services on the University of Alcala and from then he works as full-time teacher. Currently is, in addition, the chief innovation programs at the University of Alcalá. His research interests mainly focus on topics related to software engineering and knowledge representation and supervise several phD works in these areas.

M.L. Jiménez Rodríguez was born in Madrid, Spain in 1973. She got a five-year degree on Mathematics from the University Complutense of Madrid. She has been working at the University of Alcala in the Computer Science Department since May 2002. From 2004, she has been a virtual tutor of the Open University of Spain - UNED. She obtained a Ph.D. in Computer Science from University of Alcala in 2006. She has been invited to the Universitá degli Studi Roma Tre in Rome, Italy to study Ontologies for knowledge representation with the aim of Expert Systems Designment and Implementation. Recently she has supervised several Thesis.

\title{
Elektrinès audros simuliavimo panaudojimas fizikos mokymosi procesui gerinti
}

\author{
Miriam MARTÍNEZ MUÑOZ, María Lourdes JIMÉNEZ RODRÍGUEZ, \\ José Antonio GUTIÉRREZ de MESA
}

Šis darbas yra dalis tiriamojo projekto, kurio pagrindinis tikslas - išsiaiškinti, kokią įtaką informacinès ir komunikacinès technologijos turi fizikos mokymo ir mokymosi procesui. Straipsnyje parodoma, kad naudojant audros simuliavimą, studijuojančių fiziką studentų mokymasis gerèja: jie lengviau supranta audros fenomeną ir geriau suvokia fizikos idejas. Kompiuterinès technologijos formuoja sąsajas tarp edukacinio ir technologinio pasaulių, sudaro galimybes studentams naudotis dideliais informacijos ištekliais, motyvuoja mokytis, tobulina darbo rinkoje reikalingus ịūdžius ir gerina mokymosi kokybę. 